\title{
Solvent Composition Effect on PDMS Composite Dielectric Elastomer Actuator
}

\author{
Satoshi Tamura ${ }^{1,2}{ }^{*}$, Ryotaro Kiyono ${ }^{3}$, Toshihiro Hirai ${ }^{4}$ \\ ${ }^{1}$ Graduate School of Medicine, Science and Technology, Shinshu University, Nagano, Japan \\ ${ }^{2}$ Shin-Etsu Polymer Co., Ltd., Tokyo, Japan \\ ${ }^{3}$ Faculty of Engineering, Shinshu University, Nagano, Japan \\ ${ }^{4}$ Fiber Innovation Incubator, Faculty of Textile, Science and Technology, Shinshu University, Ueda, Japan \\ Email: ^18hs352k@shinshu-u.ac.jp
}

How to cite this paper: Tamura, S., Kiyono, R. and Hirai, T. (2021) Solvent Composition Effect on PDMS Composite Dielectric Elastomer Actuator. Materials Sciences and Applications, 12, 504-518. https://doi.org/10.4236/msa.2021.1211033

Received: October 12, 2021

Accepted: November 15, 2021

Published: November 18, 2021

Copyright $\odot 2021$ by author(s) and Scientific Research Publishing Inc. This work is licensed under the Creative Commons Attribution International License (CC BY 4.0).

http://creativecommons.org/licenses/by/4.0/ (c) (i) Open Access

\begin{abstract}
Polydimethylsiloxane (PDMS) is inactive to electric fields, but when combined with ferroelectric cyanoethyl sucrose (CR-U), it becomes an electrically active actuator material. The PDMS/CR-U composites were prepared by casting method using tetrahydrofuran (THF) and acetone (ACT) as solvents. The effect of a mixed solvent composition was investigated. The viscosity of the PDMS/CR-U/solvent solution decreased as the THF composition increased. The composite film obtained by evaporation of the solvent and cross-linkage of PDMS showed a phase-separated structure. Spherical CR-U dispersed in the PDMS matrix with a skin layer on one surface side. Electrical resistance, dielectric constant, space-charge distribution, and electrically induced bending deformation behavior were investigated for these composite films. The composite films prepared from a THF-rich solvent exhibited lower surface resistivity than those prepared from a THF-poor solvent. Applying an electric field to the composite film resulted in an asymmetric space-charge distribution with charge accumulation in the skin layer. THF content decreased the viscosity of the solution, meaning the decrease of the apparent size of PDMS chain aggregates. It allows the dispersion of CR-U in the PDMS matrix and also results in the decline of resistivity, the increase of permittivity, and the increase of charge injection. The results explained the structure formation of the composite film and the electric field response as an actuator. A casting solvent of THF content of $87.5 \mathrm{wt} \%$ or more is essential for the function of the PDMS/CR-U composite.
\end{abstract}

\section{Keywords}

Dielectric Actuator, Polydimethylsiloxane Composite, Solvent Composition, Morphology, Charge Accumulation 


\section{Introduction}

Smart polymer actuators are lightweight and flexible materials with high moldability and are expected to be alternatives to conventional driving devices made up of many elements. They can also be environment-friendly devices and human-friendly devices through applications to artificial muscles. The dielectric elastomer actuators driven in the air are attractive as soft and energy-efficient actuators [1] [2]. Silicone can also be a suitable material for soft actuators since elastic modulus and moldability can be freely modified. Silicone has high performance such as heat resistance, chemical resistance, and light resistance [3].

Pelrine et al. made electrical actuators from films of silicone coated on both sides with a compliant electrode material [4] [5]. When voltage was applied, the resulting electrostatic forces compressed the film in thickness and expanded it in area. The strains up to $117 \%$ with silicone elastomers were attained by prestraining the film. Wiranata et al. investigated a simple and reliable fabrication method for polydimethylsiloxane (PDMS) dielectric elastomer actuators using carbon nanotube powder electrode [6]. They reported that the brushing of CNT combined with soft and sticky elastomer membranes can increase dielectric elastomer actuators' performance. Yang et al. reported that silicone rubber composites exhibited significantly improved electromechanical properties via tuning the molecular flexibility by adding plasticizer [7]. The result indicates that tuning flexibility of composites is a good strategy to obtain high-performance dielectric elastomers. Gao et al. investigated silicone elastomer composites containing $\mathrm{TiO}_{2} @ \mathrm{SiO}_{2}$ core-shell nanoparticles [8]. They showed the core-shell structure can play an important role in both improving the electromechanical actuation property and maintaining good flexibility of dielectric elastomer composites. Inoue et al. reported the electrical properties and actuator behavior of composite films of ionic liquid/PDMS (polydimethylsiloxane) gels [9]. The deformation mechanism based on the electrical interaction between the electrode and the ionic liquid was discussed. The deformation mechanism was concluded similarly to ionic polymer-metal composite due to the large current flows in proportion to the voltage.

The authors have been investigated the dielectric silicone composite actuators with a polar group material [10] [11]. PDMS is inactive to electric fields by itself, but when combined with ferroelectric materials, it can be an electrically active actuator material. In particular, the PDMS and cyanoethyl sucrose (CR-U) composite prepared by the solution casting method exhibited significant bending deformation. Since CR-U has a very high viscosity, the PDMS composites were prepared using tetrahydrofuran (THF) and acetone (ACT), good solvents for CR-U.

The film prepared using ACT had asymmetric cross-sectional structure, in which small CR-U spheres dispersed uniformly. On the other hand, the films prepared using THF had an asymmetric cross-section, a thin-skin layer on one side of the film, and sizable CR-U spheres dispersed in the film body. 
The composite films prepared with THF as solvent showed bending deformation behavior in response to an electric field, but those with ACT as solvent did none. From the space-charge distribution analysis, a charge accumulation was observed in the skin layer of the film made with THF, and the repulsion of this accumulated charge was suggested to have caused bending deformation. However, it has to be clarified why the composite structure from ACT is electrically inactive, and the non-uniform dispersion structure from THF is electrically active as an actuator. In other words, how the solvent composition affects the composite structure, and how the structure develops in the composite are not clarified.

In this study, the THF/ACT ratio of the casting solution was varied from $100 / 0$ to $0 / 100$ to investigate the relationship between the morphology of the PDMS composites with CR-U and bending deformation. The viscosity of PDMS/CR-U/solvent was measured. The composite films' morphology, surface resistivity, bending deformation, and space-charge distribution were also investigated. Then, the mechanism of the morphology formation and its effect on the actuator function were discussed.

\section{Experimental}

\subsection{Materials}

SILPOT184/CAT184 (DuPont Toray Specialty Materials K.K.) was used as PDMS. It is an additional reaction type PDMS. As polar group-containing materials, cyanoethyl sucrose CR-U (Shin-Etsu Chemical Co., Ltd.), which possesses a cyanoethyl group $\left(-\mathrm{CH}_{2} \mathrm{CH}_{2} \mathrm{CN}\right)$ was used.

\subsection{Preparation of PDMS/CR-U/Solvent Cast Solutions}

The base SILPOT184 and curing agent CAT184 were mixed in a weight ratio of 10:1 as a PDMS solution. CR-U is very viscous and difficult to handle as it is but is soluble in THF and ACT [12] [13] [14]. Thus, $50 \mathrm{wt} \%$ CR-U solutions of THF (CR-U (T)) and ACT (CR-U (A)) were prepared. CR-U (T) and CR-U (A) were mixed with PDMS solution so that the CR-U content to the base SILPOT184 and CAT184 was $42.9 \mathrm{wt} \%$, at which the maximum bending deformation under an electric field was attained [10] [11]. THF/ACT weight ratio was from $0 / 100$ to 100/0. They were stirred at $2000 \mathrm{rpm}$ for $6 \mathrm{~min}$ using a revolution stirrer (ARE-310, THINKY Co., Ltd.) to prepare a "cast solution" of PDMS/CR-U/solvent. Table 1 shows the composition of PDMS/CR-U/solvent cast solution.

\subsection{Preparation of Composite Films}

The cast solutions were poured onto a PET film and were cast with a four-sided film applicator (052-6, All Good Co., Ltd.). The solutions were kept for $30 \mathrm{~min}$ at room temperature, and then heated and cured in an oven at $150^{\circ} \mathrm{C}$ for $30 \mathrm{~min}$. The surface in contact with air and PET film was defined as "AIR-side" and "PET-side" respectively. PDMS composite films of PDMS/CR-U (Ax/Ty) were 
Table 1. Composition and viscosity of PDMS/CR-U/solvent cast solution, tensile elastic modulus and dielectric constant of composite films.

\begin{tabular}{|c|c|c|c|c|c|c|c|c|}
\hline & Material Name & PDMS & $\begin{array}{c}\text { PDMS/CR-U } \\
\text { (A100/T0) }\end{array}$ & $\begin{array}{l}\text { PDMS/CR-U } \\
\text { (A75/T25) }\end{array}$ & $\begin{array}{l}\text { PDMS/CR-U } \\
\text { (A50/T50) }\end{array}$ & $\begin{array}{l}\text { PDMS/CR-U } \\
\text { (A25/T75) }\end{array}$ & $\begin{array}{l}\text { PDMS/CR-U } \\
\text { (A12.5/T87.5) }\end{array}$ & $\begin{array}{l}\text { PDMS/CR-U } \\
\text { (A0/T100) }\end{array}$ \\
\hline \multirow{6}{*}{ 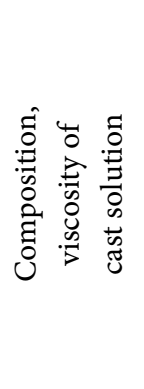 } & SILPOT184 & 10.0 & 10.0 & 10.0 & 10.0 & 10.0 & 10.0 & 10.0 \\
\hline & CAT184 & 1.0 & 1.0 & 1.0 & 1.0 & 1.0 & 1.0 & 1.0 \\
\hline & CR-U & - & 8.3 & 8.3 & 8.3 & 8.3 & 8.3 & 8.3 \\
\hline & $\mathrm{ACT}$ & - & 8.3 & 6.2 & 4.1 & 2.1 & 1.0 & 0.0 \\
\hline & THF & - & 0.0 & 2.1 & 4.1 & 6.2 & 7.2 & 8.3 \\
\hline & Viscosity $(\mathrm{Pa} \cdot \mathrm{S})$ & - & 11.00 & 5.2 & 1.29 & 0.51 & 0.30 & 0.27 \\
\hline \multirow{2}{*}{ 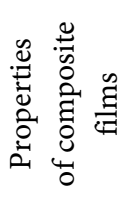 } & $\begin{array}{l}\text { Tensile Elastic } \\
\text { Modulus (MPa) }\end{array}$ & 1.80 & 0.80 & 0.90 & 0.85 & 0.86 & 0.92 & 0.95 \\
\hline & $\begin{array}{c}\text { Dielectric constant } \\
(500 \mathrm{~V} \times 1 \mathrm{~Hz})\end{array}$ & 2.90 & 6.92 & 8.09 & 8.40 & 8.52 & 8.68 & 8.76 \\
\hline
\end{tabular}

prepared, where $x$ and $y$ were ACT and THF content (wt\%) to the total amount of solvent, respectively. THF content was defined as the weight ratio against the total solvents.

\subsection{Properties of Cast Solution and Composite Films}

The viscosities of cast solutions were measured with the tuning-fork vibrometers (SV-10A, A \& D Instrument Ltd.) at $20^{\circ} \mathrm{C}$.

The cross-sectional images were observed with a laser microscope (OLYMPUS LEXT OLS4100, Olympus Corporation).

The tensile elastic modulus of the PDMS composites was measured using a tensilon-tensile measuring device (RTC-1250A, A \& D Co., Ltd.). The PDMS composites were strained at $50 \mathrm{~mm} / \mathrm{min}$ in a $10 \mathrm{~N}$ load cell. The tensile elastic modulus was calculated from the initial slope of the tensile stress curve at low tensile stress.

The dielectric constant was measured with an impedance analyzer (SI1260 and SII1296, Solartron Co., Ltd.), high voltage interface (HVI-100, TOYO Corporation), and bipolar amplifier (BOP-1000M, KEPCO, INC.). The dielectric constant $(1 \mathrm{~Hz})$ under a constant voltage was measured under $500 \mathrm{~V}$ because the dielectric actuator is driven by applying a voltage.

The surface resistivity was measured with a resistivity meter (Hiresta-UX MCP-HT800, probe type "URS", Nittoseiko Analytech). The applied voltage was $500 \mathrm{~V}$, a similar electric field for the bending deformation and space-charge distribution measurements.

\subsection{Bending Deformation}

Figure 1 shows the specimen dimensions and the experimental setup for mea- 
suring bending deformation. The PDMS composite film was cut to a width of 5 $\mathrm{mm}$ and a length of $20 \mathrm{~mm}$, and two sheets of gold foils having a width of $4 \mathrm{~mm}$, a length of $15 \mathrm{~mm}$, and a thickness of $0.1 \mu \mathrm{m}$ (KATANI SANGYO Co., Ltd.) were attached to both surfaces of the film to obtain a specimen. A maximum output of $850 \mathrm{~V}$ (square wave output) was used as a DC power source. One side of the specimen was fixed with the Kelvin clip ( $12 \mathrm{~mm}$ from the clip to the tip of the specimen was set in a cantilever state) and was settled perpendicularly to the floor surface. A $3 \mathrm{kV} / \mathrm{mm}$ DC voltage was applied between the gold foils of a specimen to observe the bending deformation as shown in Figure 1. First, the electric field was applied for 30 minutes so that the AIR-side (skin layer side) was the anode. Then, the polarity of the electric field was reversed. The bending deformation was observed and analyzed with a digital microscope.

\subsection{Space-Charge Distribution}

The space-charge distribution was measured with a Pulsed Electrostatic Acoustic Non-destructive Test System (PEANUT) manufactured by Five Lab Co., Ltd [10] [11] [15] [16] [17] [18]. The specimens were sandwiched between the upper (semiconductive rubber) and lower (aluminum) electrodes. A pulsed electrostatic force acts on a charge in the specimen, and an elastic wave, which has information of the charge distribution, is generated. This elastic wave is converted into an electric signal by a piezoelectric element, and then into the space-charge distribution. Bias conditions were $3 \mathrm{kV} / \mathrm{mm}$, and pulse conditions were $200 \mathrm{~V} \times$ $400 \mathrm{~Hz}$.

\section{Results and Discussion}

\subsection{Viscosity}

The viscosities of the cast solutions of PDMS/CR-U composites are shown in Table 1. The viscosity of the cast solution decreased from 11.00 Pa.S (PDMS/CR-U (A100/T0)) to 0.27 (PDMS/CR-U (A0/T100)) with the THF content.

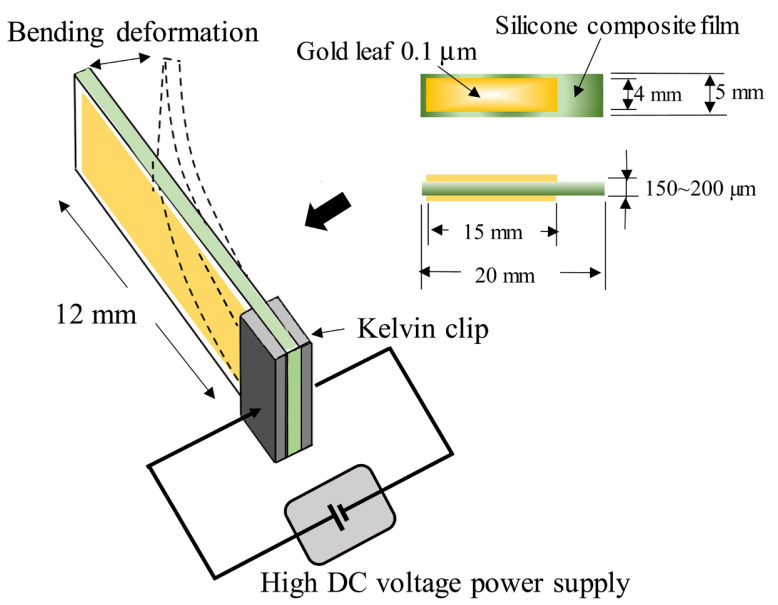

Figure 1. The specimen dimensions and experimental setup for bending deformation measurement. 


\subsection{Morphology (Phase-Separation and Cross-Sectional Structure)}

The film thickness of PDMS/CR-U composites was 150 to $200 \mathrm{~mm}$. The thickness depends on the viscosity of the PDMS/CR-U/solvent solution. The higher the viscosity was, the thicker the thickness was. As shown in Figure 2, the cross-sectional images of the PDMS/CR-U composites showed a phase-separated structure, in which CR-U spheres dispersed in the PDMS continuous matrix. PDMS/CR-U (A100/T0) showed a symmetric cross-sectional, in which CR-U small spheres dispersed uniformly. On the other hand, PDMS/CR-U (A0/T100) composites showed an asymmetric cross-sectional structure in which CR-U large spheres dispersed in the PDMS matrix with a skin layer on one surface side.

Figure 2 also shows THF content dependence of CR-U spherical diameter and the thin-skin layer thickness obtained by cross-sectional image analysis of PDMS composite films. The CR-U sphere diameter gradually increased with THF content, but the thin-skin layer thickness increased significantly at THF content 87.5 $\mathrm{wt} \%$ or more. Thus, the morphology changed significantly from a symmetric to an asymmetric at THF content $87.5 \mathrm{wt} \%$ or more.

\subsection{Elastic Modulus}

The tensile elastic modulus of PDMS/CR-U composites is shown in Table 1. The tensile elastic modulus of composite films was lower than that of PDMS prepared without solvent (1.8 $\mathrm{MPa})$. The tensile elastic modulus increased slightly with THF content. PDMS/CR-U (A0/T100) showed almost $1 \mathrm{MPa}$ and possessed sufficient mechanical strength for practical use.

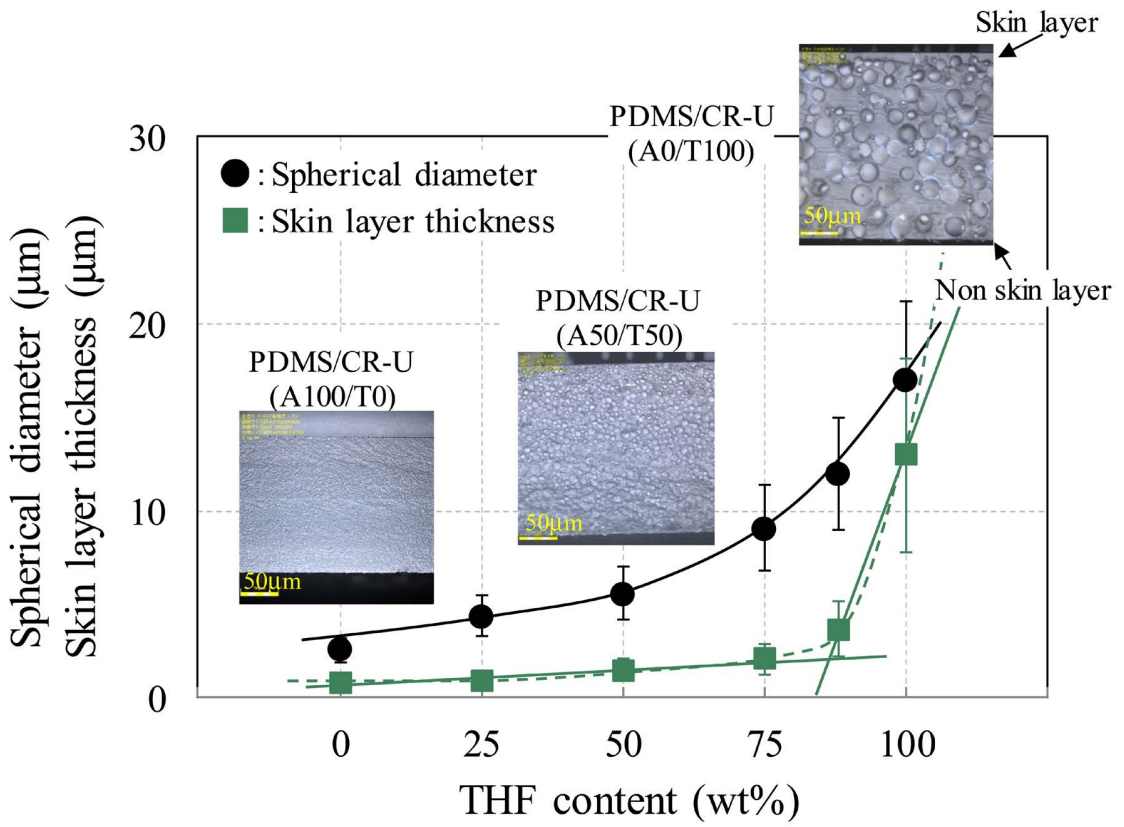

Figure 2. THF content dependence of spherical diameter and the thin-skin layer thickness, and cross-sectional images. 


\subsection{Dielectric Constant}

The dielectric constant of PDMS/CR-U composites is shown in Table 1. The dielectric constants of pure PDMS and PDMS/CR-U (A0/T100) were 2.9 and 8.76, respectively. The dielectric constant increased slightly with THF content.

\subsection{Surface Resistivity}

Figure 3 shows the AIR- and PET-side surface resistivity of PDMS/CR-U composites films. The surface resistivity of pure viscose CR-U and pure PDMS film (without CR-U) were also shown as a reference. The surface resistivity on both sides of the composite films at THF content of $75 \mathrm{wt} \%$ and less were higher than $10^{14} \Omega$ and out of range as well as pure PDMS. On the other hand, the surface resistivity of PDMS/CR-U (A0/T100) and (A12.5/T87.5) were about $10^{13} \Omega$ which was lower than that of PDMS but higher than that of CR-U. The surface resistivity of PDMS/CR-U (A0/T100) was higher than that of PDMS/CR-U (A12.5/T87.5), which suggests the increase in THF content allows the dispersion of CR-U in the PDMS phase.

\subsection{Bending Deformation Behavior}

Figure 4 shows the time dependence of bending deformation of PDMS/CR-U composites under a $3 \mathrm{kV} / \mathrm{mm}$ electric field. The electric field was applied at $t=0$ so that the AIR-side electrode became anode and released at $t=30 \mathrm{~min}$. Negative values of the deformation indicate that the film has bent toward the PET-side. The deformation increased immediately after the voltage turned on and gradually reached a steady state with time. The deformation after the voltage off decreased instantly and recovered a steady state remaining some hysteresis in 10 minutes. The bending deformation was defined as the difference between the two steady states.

In Figure 5, the bending deformation of composite films was plotted against THF content. The bending deformation of the composite films at THF content

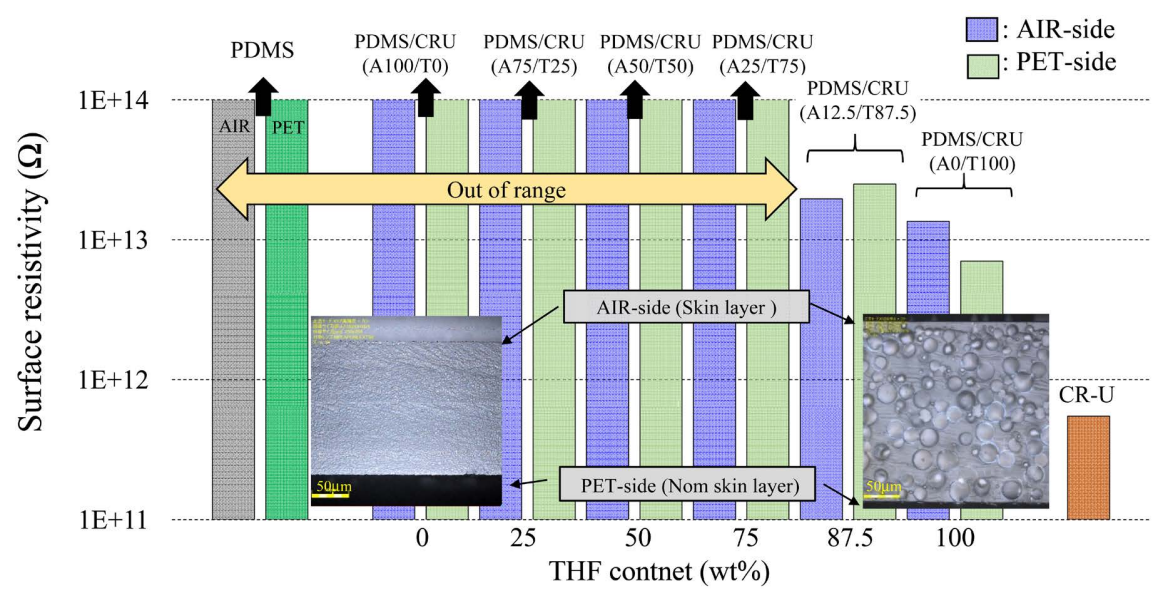

Figure 3. Surface resistivity of PDMS/CR-U composites, PDMS and CR-U. Probe type: URS. Voltage condition: $500 \mathrm{~V} \times 10 \mathrm{sec}$. 


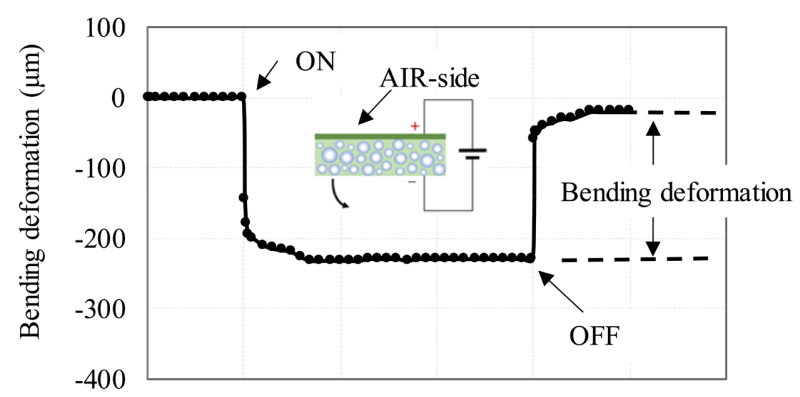

(A)

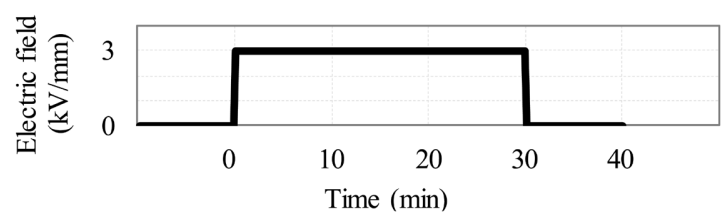

(B)

Figure 4. Time dependence of bending deformation (A) and electric field (B).

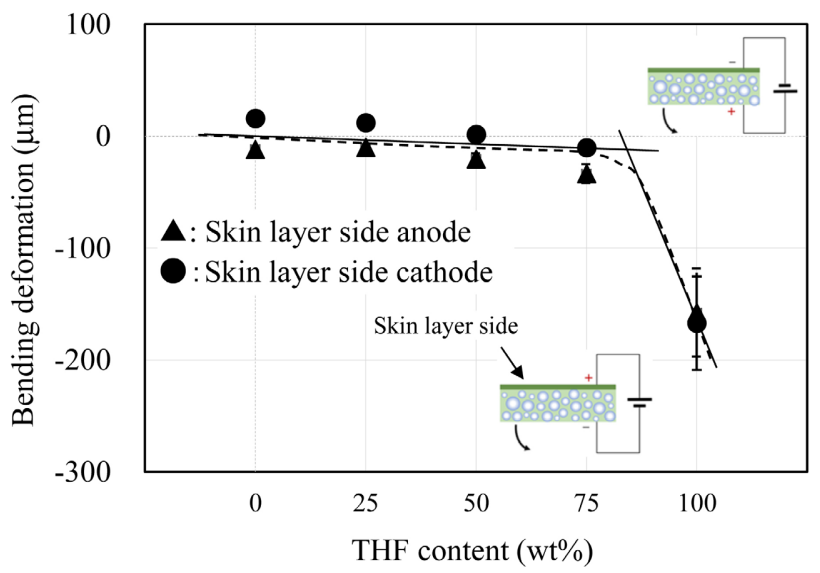

Figure 5. Relationship between the bending deformation and THF content. Electric field strength: $3 \mathrm{kV} / \mathrm{mm}$.

$75 \mathrm{wt} \%$ or less was remarkably small. On the other hand, the composite showed substantial bending deformation when the morphology changed to an asymmetric cross-sectional structure at THF content of $87.5 \mathrm{wt} \%$ or more.

\subsection{Space-Charge Distribution}

Figure 6 shows the space-charge distribution of PDMS/CR-U composites. The horizontal axis represents the sample thickness (position). The electrode interfaces were defined as zero, and the vertical axis represents the space-charge density. The maximum value of the opposite charge accumulated in the film in the vicinity of the AIR-side electrode interface was defined as the hetero charge value.

In Figure 6(A), the interface of the anode/AIR-side (skin layer side) is defined as zero of the depth axes. The accumulation of a small and significantly large negative charge (shown by diagonal lines in the figure), which is the opposite to 


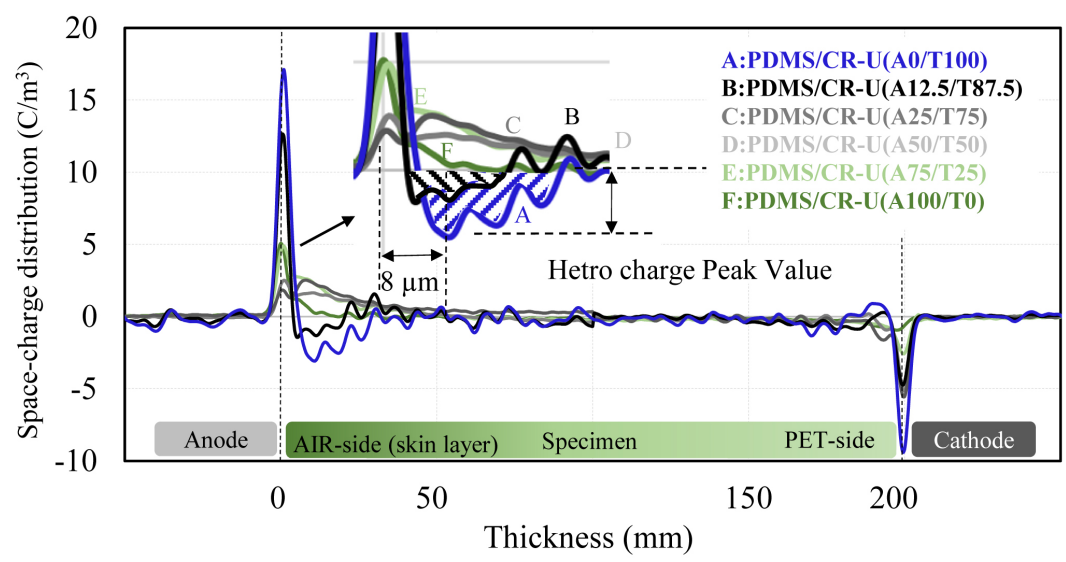

(A)

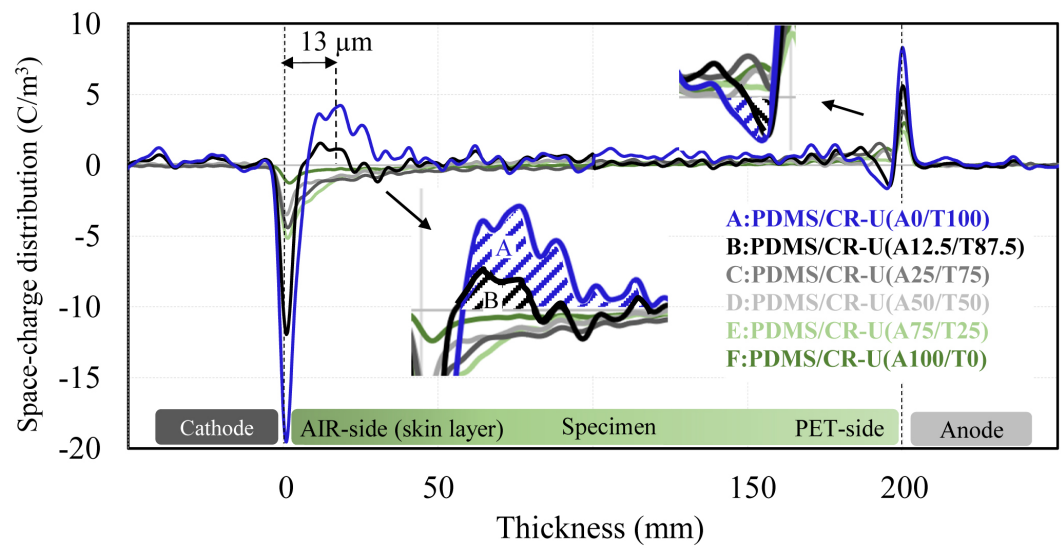

(B)

Figure 6. Space-charge distribution: (A) AIR-side attached to anode, (B) AIR-side attached to cathode.

the polarity of the anode, that is, the hetero charge was observed inside the PDMS/CR-U (A12.5/T87.5) and PDMS/CR-U (A0/T100), respectively, in the vicinity of the anode interface. The hetero (positive) charge accumulation was not almost observed inside the film near the cathode interface, thus, the asymmetry of the space-charge distribution was confirmed. On the other hand, the space-charge distribution of PDMS/CR-U (A100/T0) to (A25/T75) showed no hetero charge accumulation inside the film.

In Figure 6(B), the cathode electrode/AIR-side of the film interface is defined as zero of the depth axes. The hetero charge accumulation of PDMS/CR-U (A0/T100) and PDMS/CR-U (A12.5/T87.5) was confirmed in the vicinity of both electrodes, and the accumulation at the cathode side was more extensive than that at the anode side. As a result, an asymmetry of the space-charge distribution was confirmed. On the other hand, the space-charge distribution of PDMS/CR-U (A100/T0) to (A25/T75) showed no hetero charge accumulation inside the film.

PDMS/CR-U (A0/T100) to (A12.5/T87.5) indicated the significant hetero charge accumulation in the vicinity of the AIR-side/electrode interface regard- 
less of the electric field polarity. The location of the hetero charge accumulation was nearly consistent with that of the thin-skin layer. Thus, the thin-skin layer suppressed the electric charge leakage, and the electric charge was accumulated in the vicinity of the thin-skin layer. The composite showed the asymmetric space-charge distribution when the morphology changed to an asymmetric cross-sectional structure at THF content of $87.5 \mathrm{wt} \%$ or more.

\subsection{Hetero Charge Value}

Figure 7 shows the relationship between the hetero charge value of the AIR-side (thin-skin layer side) estimated from Figure 6 and THF content. The hetero charge value was not observed for the composite films at THF content of 0 to 75 $\mathrm{wt} \%$, however, the charge accumulation was increased significantly at THF content $87.5 \mathrm{wt} \%$ or more regardless of the electric field polarity.

For PDMS/CR-U (A100/T0) to PDMS/CR-U (A25/T75), the charge injection did not occur when (even if) the electric field was applied because of their high surface resistivity. As a result, the composites showed almost no bending deformation. The significant increase in hetero charge was consistent with the bending deformation of the PDMS/CR-U composite. The charge accumulation is a primary factor for bending deformation. The bending deformation was due to the electrostatic repulsion among the charges that caused the thin-skin layer expansion induced the bending deformation.

\subsection{Phase-Separation Formation Process}

The morphology of the composite film strongly depends on the (composition of the) casting solution. So, first, the viscosity of the solutions of PDMS/CR-U/solvent was discussed. The viscosity of polymer solutions is sometimes helpful to get insight into the polymer morphology in the solution. Figure 8 is a plot of the viscosity $\eta$ against THF content. The $\eta$ decreased sharply with the THF content and showed a constant low value above the THF content of $87.5 \mathrm{wt} \%$.

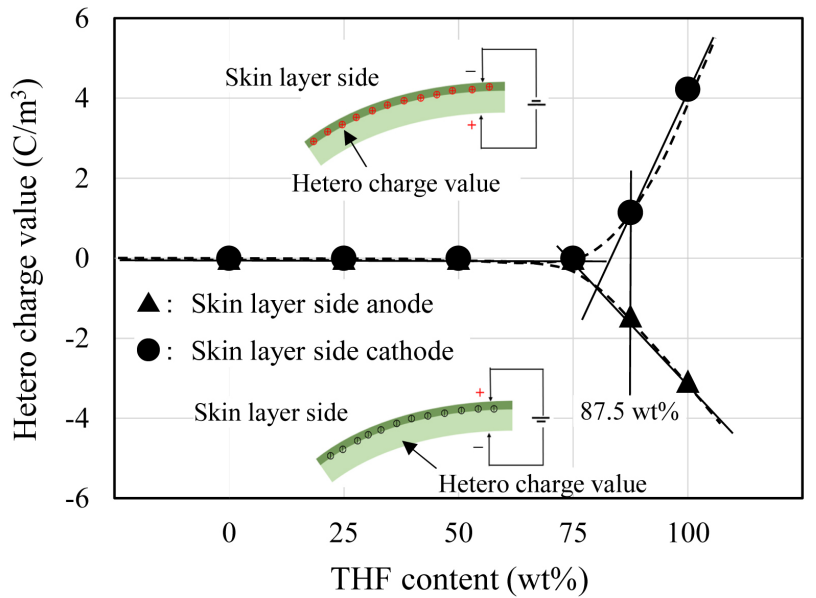

Figure 7. Relationship between the hetero charge value and THF content. Electric field: 3 $\mathrm{kV} / \mathrm{mm}$. 


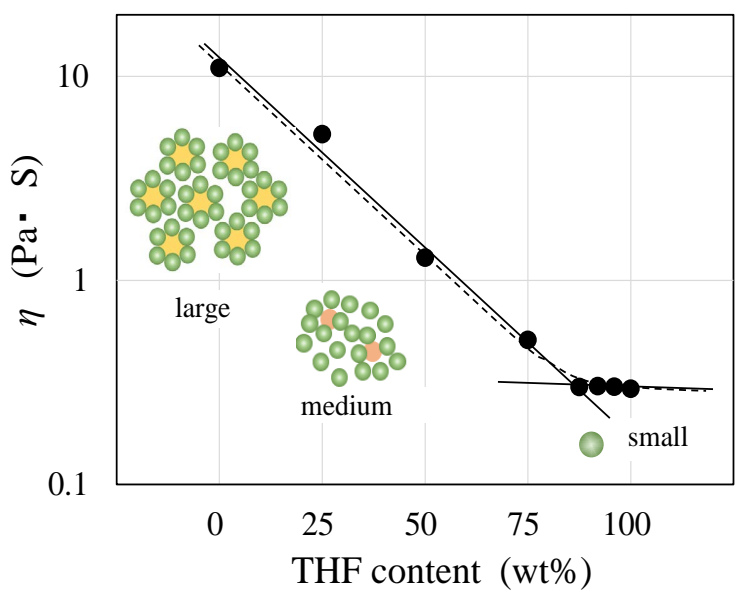

Figure 8. The viscosity of PDMS/CR-U/solvent solution on THF content.

In the high concentration polymer system, the viscosity is very sensitive to the polymer chain length. $\eta$ increases with $N$ (number of monomers (units) in a polymer chain), according to the Equation (1) [19]:

$$
\eta \sim N^{m_{\eta}}
$$

where $m_{\eta}$ is scaled 3.3 - 3.5, which is still controversial. When the relation of Equation (1) can be applied to the authors' system, the change of $N$, an apparent size of PDMS aggregates can be reflected in the change of $\eta$. No matter the value of $m_{\eta}$ is, the larger the $\eta$, the bigger the $N$. Then, the following discussion will be available:

In solutions with a THF content of $87.5 \mathrm{wt} \%$ or more, $\eta$ reached a certain small value. In other words, small PDMS chain aggregates were distributed in the CR-U containing solution. On the contrary, the aggregate size increased with ACT content. Furthermore, the PDMS/CR-U (A100/T0) solution became paste-like sol right after mixing, suggesting the CR-U solution is secluded in the large aggregates of PDMS chains by micellization.

The morphology of the composite film is strongly dependent on the casting solvent. Figure 9 illustrates a schematic diagram of the morphology formation (after curing).

Figure 9(A) shows a schematic diagram of the PDMS/CR-U (A0/T100) to (A12.5/T87.5) solution and the composite.

Since CR-U is miscible in THF and ACT, CR-U dissolves in any composition of THF-ACT solvent. PDMS is also soluble in THF-rich solvents. However, when PDMS solution and CR-U solution are mixed, the mixture instantly forms an untransparent dispersion. The PDMS phase, which has a small size PDMS aggregate, is dispersed in a CR-U solution of THF-ACT. As shown in (a) of Figure 9(A), the PDMS (green sphere) with a smaller PDMS aggregates is highly mobile and less viscous.

As PDMS aggregates with the solvent evaporation and the progress of crosslinking, CR-U is gradually squeezed out from the PDMS aggregates and forms a droplet phase of CR-U, accompanying the sedimentation of the CR-U droplet, 


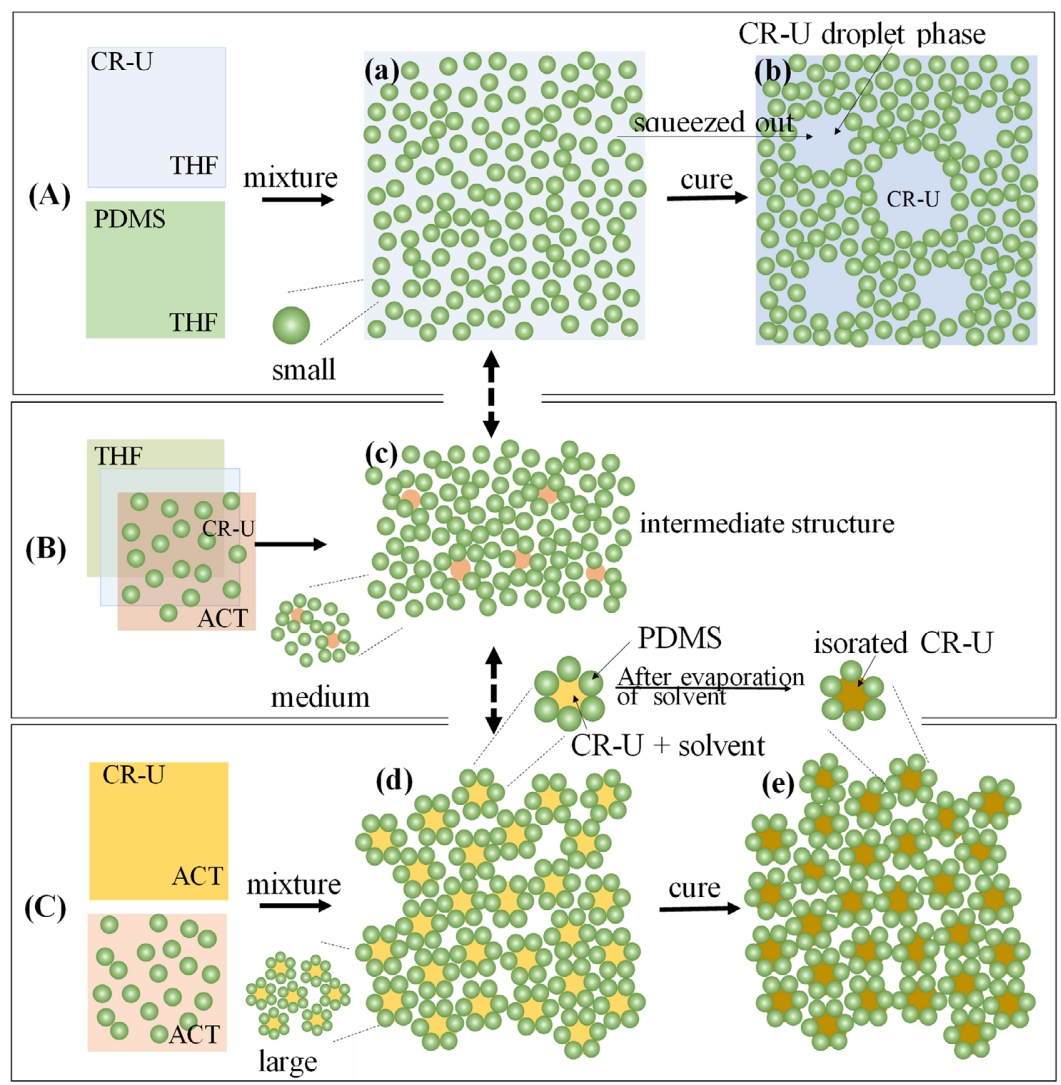

Figure 9. Schematic diagram of the phase-separation of the cast solution and the composites: (A) THF rich phase-separation with low resistivity, (B) ACT/THF $=50 / 50 \mathrm{wt} \%$ phase-separation, (C) ACT rich phase-separation with high resistivity.

because the density of CR-U $\left(1.23 \mathrm{~g} / \mathrm{cm}^{3}\right)$ [14] is higher than that of PDMS (1.03 $\mathrm{g} / \mathrm{cm}^{3}$ ) [20]. Therefore, CR-U droplet phases settle during the evaporation/curing process (film formation) in the middle of sedimentation. On the other hand, the sedimentation process accompanies the skin layer formation in the airside of the film. The phenomenon is observed in the films in the range of PDMS/CR-U (A0/T100) to (A12.5/T87.5). Thus, an asymmetrical PDMS/CR-U film with a PDMS skin layer is formed and some CR-U remains in the thin skin layer and the film matrix even after curing.

As shown in Table 1, the segregation and gradual curing process of PDMS in the film result in a slight increase in the tensile modulus due to the compaction of the PDMS phase and the dielectric constant due to the CR-U continuous channel remaining in the PDMS phase. In addition, the increased permittivity facilitates charge injection, and the dense skin layer prevents discharge, thus inducing an asymmetric space-charge distribution. Thus, the composite becomes electrically active. As a result, the film can bend when an electric field is applied and be used for dielectric actuators.

Figure 9(B) shows the case of a PDMS/CR-U (A50/T50) solution. It is an intermediate case of Figure 9(A) and Figure 9(C). Therefore, in Figure 9(B), PDMS aggregates are intermediate size. The morphology of the composite film 
also displays an intermediate structure. However, the PDMS phase contained almost no CR-U, and the composite material is an insulator to an electric field similar to Figure $9(\mathrm{C})$.

Figure 9(C) shows a schematic diagram of a PDMS/CR-U composite ranging the solvent composition from (A100/T0) to (A75/T25). PDMS is immiscible in ACT but is colloidally dispersed in ACT-rich THF solvent. Immediately after mixing a PDMS solution and a CR-U solution, the aggregates of PDMS molecules instantly seclude the CR-U solution to form paste-like aggregates, as shown in (d) of Figure 9(C). The CR-U solution is covered with PDMS aggregates. The micelles have large PDMS aggregates, and the aggregates grow by hydrophobic interactions. Therefore, the solution showed high viscosity immediately after mixing.

The composite film obtained by evaporating the solvent in the micelle and curing the PDMS has the finely dispersed CR-U domain coated with PDMS, and the CR-U phase remains isolated and finely dispersed as shown in (e) of Figure 9(C). CR-U is not included in the PDMS matrix, since PDMS forms a continuous phase right after mixing. Therefore, the composite has a symmetrical cross-sectional structure, a small and evenly dispersed CR-U phase, and exhibits high electrical insulation properties. This insulation characteristic effectively suppressed bending deformation.

\section{Conclusions}

In this study, composite films of PDMS and CR-U were prepared using solutions of THF and ACT. The effect of the solution composition on the bending deformation behavior of the films was investigated. The main conclusions are as follows:

1) THF, which is miscible in PDMS and CR-U, induced the diffusion of CR-U in the PDMS phase. The morphology induced a drastic or discontinuous change to an asymmetric cross-sectional structure at THF content of $87.5 \mathrm{wt} \%$ or more.

2) The hetero charge accumulation in the thin-skin layer increased sharply from THF content $87.5 \mathrm{wt} \%$ or more regardless of the electric field polarity. The charge accumulation is a primary factor for bending deformation.

3) A small amount of ACT with a low affinity for PDMS suppressed the diffusion of CR-U and greatly affected the morphology of the composites. The composites from THF content $75 \mathrm{wt} \%$ or less showed asymmetry cross-section and allowed no charge injection and almost no bending deformation.

Controlling the phase separation process of the cast solution had a significant influence on the morphology of the composite and the manipulation of an asymmetric space-charge distribution. THF content of the casting solvent played a critical role in the bending deformation behavior of dielectric actuators of PDMS/CR-U composites. Therefore, combining high miscibility solvent for polymer (PDMS) and polar material (CR-U) provide a good candidate for an electrically active silicone dielectric actuator. 


\section{Acknowledgements}

The authors would like to express our deepest gratitude to Shin-Etsu Chemical Co., Ltd. which provided cyanoethyl sucrose materials. The authors are also deeply grateful to Mr. Shusuke Nagamura of Five Lab Co., Ltd. who gave us advice for space-charge measurement.

\section{Conflicts of Interest}

The authors declare no conflicts of interest regarding the publication of this paper.

\section{References}

[1] Hirai, T. and Xia, H. (2015) Chapter 1. Electric Functions of Textile Polymers. In: Tao, X., Ed., Handbook of Smart Textiles, Springer, Singapore, 3-29. https://doi.org/10.1007/978-981-4451-45-1_8

[2] Asaka, K. and Okuzaki, H. (2019) Soft Actuators. Springer, Singapore. https://doi.org/10.1007/978-981-13-6850-9

[3] Yamatani, M. (2016) Silicon Daizenshu. Nikkan Kogyo Shimbun, 1-11.

[4] Pelrine, R., Kornbluh, R., Pei, Q. and Joseph, J. (200) High-Speed Electrically Actuated Elastomers with Strain Greater than 100\%. Science, 287, 836-839. https://doi.org/10.1126/science.287.5454.836

[5] Pe1rine, R., Larsen, P.S., Kornbluh, R., Heydt, R., Kofod, G., Pei, Q. and Gravesen, P. (2001) Applications of Dielectric Elastomer Actuators. Proceedings of SPIE, 4329, 335-349. https://doi.org/10.1117/12.432665

[6] Wiranata, A., Ishii, Y., Hosoya, A. and Maeda, S. (2021) Simple and Reliable Fabrication Method For Polydimethylsiloxane Dielectric Elastomer Actuators Using Carbon Nanotube Powder Electrodes. Advanced Engineering Materials, 23, Article ID: 2001181. https://doi.org/10.1002/adem.202001181

[7] Yang, D., Huang, S., Ruan, M., Li, S., Wu, Y., Guo, W. and Zhang, L. (2018) Improved Electromechanical Properties of Silicone Dielectric Elastomer Composites by Tuning Molecular Flexibility. Composites Science and Technology, 155, 160-168. https://doi.org/10.1016/j.compscitech.2017.12.010

[8] Gao, S., Zhao, H., Zhang, N. and Bai, J. (2021) Enhanced Electromechanical Property of Silicone Elastomer Composites Containing $\mathrm{TiO}_{2} @ \mathrm{SiO}_{2}$ Core-Shell Nano-Architectures. Polymers, 13, Article No. 368. https://doi.org/10.3390/polym13030368

[9] Inoue, Y., Yan, H. and Okuzaki, H. (2011) Electromechanical Properties and Actuating Behavior of Ionic Liquid/Polydimethylsiloxane Gels. Kobunshi Ronbunshu, 68, 122-126. https://doi.org/10.1295/koron.68.122

[10] Tamura, S., Kiyono, R. and Hirai, T. (2020) Dielectric Actuator Behavior and Space-Charge Distribution of Silicone Composites Containing Polar Groups. Transactions of the Materials Research Society of Japan, 45, 143-148. https://doi.org/10.14723/tmrsj.45.143

[11] Tamura, S., Kiyono, R. and Hirai, T. (2021) Dielectric Elastomer Actuator Behavior of Silicone/Cyanoethylsucrose Composite Films: Morphology and Space-Charge Distribution. Nano Select, 1-11. https://doi.org/10.1002/nano.202100023

[12] Maruyama, K., Fukui, N. and Kaneko, T. (1991) Ciano Resin. Polyfile, 28, 44-47.

[13] Kinbara, S., Tasaka, S. and Inagaki, N. (1993) Molecular Motion and Dielectricity in 
Polymers with Cyanoethyl Group. Sen' $i$ Gakkaishi, 49, 48-53.

https://doi.org/10.2115/fiber.49.6

[14] Shin-Etsu Chemical Co., Ltd. (2018) “Cyano Resin” Technical Information.

[15] Mizutani, S. (1995) Space Charge Distribution Insulating Polymers. Proceedings of the Institute of Electrostatics Japan, 19, 350-357.

[16] Fukunaga, K. and Maeno, T. (1995) Measurement of the Space Charge Distribution for the Study of the Electrostatic Phenomena. IEEJ Transactions on Electronics, Information and Systems, 115-C, 558-562.

https://doi.org/10.1541/ieejeiss1987.115.4_558

[17] Liang, L., Liang, F., Xia, W. and Demin, T. (2003) Space Charge Formation in Silicone Rubber. Proceedings of the 7 th International Conference on Properties and Applications of Dielectric Materials, Nagoya, 1-5 June 2003, 669-672. https://doi.org/10.1109/ICPADM.2003.1218506

[18] Murakami, T., Shiba, R. and Takai, H. (1997) Effect of Stabilizer on Space Charge Accumulation and Characteristic of Leakage Current Density in PVC. IEEJ Transactions on Electronics, Information and Systems, 117-A, No. 6, 647-648.

[19] de Gennes, P.D. (1979) Scaling Concepts in Polymer Physics. Cornell University Press, Ithaca and London.

[20] DuPont Toray Specialty Materials K.K. (2003) Product Safety Data Sheet, Version: 1.4, Revision D. 